\title{
COEFICIENTES DE ASSIMETRIA E CURTOSE NOS DADOS DE VAZÃO MÉDIA MENSAL DA BACIA DO RIO PRETO-BA
}

\author{
Eduardo Petrucci $^{(a)}$, Luiz Antônio de Oliveira ${ }^{(b)}$ \\ (a)Instituto de Geografia, Universidade Federal de Uberlândia, eduardo11sp@ hotmail.com \\ ${ }^{(b)}$ Instituto de Geografia, Universidade Federal de Uberlândia, luiz_ao@msn.com
}

\section{EIXO: BACIAS HIDROGRÁFICAS E RECURSOS HÍDRICOS: ANÁLISE, PLANEJAMENTO E GESTÃO}

\section{Resumo}

Técnicas estatísticas aplicadas às vazões podem trazer resultados que refinam a análise e o tratamento de dados trabalhados. Podem trazer informações sobre a variável, mais do que a própria tabela original de dados brutos. A partir disso, foi objetivado calcular a Assimetria (por meio do Coeficiente de Pearson) e o Coeficiente de Curtose de três postos fluviométricos do Rio Preto-BA, sob responsabilidade de ANA (Agência Nacional das Águas). Os dados de vazões médias mensais foram obtidos por meio do sítio eletrônico do Hidroweb, do período de 1970-2015. A partir do cálculo dos coeficientes de assimetria e curtose, verificou-se que os postos Ibipetuba e Fazenda Porto Limpo apresentaram assimetria negativa, o primeiro deles forte assimetria e o segundo assimetria moderada. $\mathrm{O}$ posto Formosa do Rio Preto apresentou forte assimetria positiva. Referente à curtose, os dois primeiros postos foram classificados como distribuição platicúrtica, e o terceiro distribuição mesocúrtica.

Palavras chave:vazões; coeficiente de assimetria; coeficiente de curtose; bacia hidrográfica; Bahia.

\section{Introdução}

O estudo relacionado às vazões é de fundamental importância para a compreensão do comportamento hidrológico de um rio e da bacia hidrográfica correspondente. O conhecimento acerca dessa variável contribui, entretanto, para estimar os períodos de seca ou estiagem, de cheias, a velocidade do escoamento e transporte de sedimentos, para a predição de obras de engenharia, disponibilização de água para os distintos usos, entre outros.

Segundo Pinto (1976), a vazão é "o volume de água escoado na unidade de tempo de uma determinada seção do curso de água" (p. 38), habitualmente expressa em metros cúbicos por segundo $\left(\mathrm{m}^{3} / \mathrm{s}\right)$.Comumente, as abordagens em vazões podem ser em dadosde mínimas, médias e máximas e, podem variar espacial e temporalmente.A variação espacial da vazão se dá a partir da medição e coleta em vários pontos do mesmo canal fluvial ou em diversos postos dentro de uma bacia hidrográfica. A variação temporal pode ser a partir de uma série de dados horários, diários, mensais, anuais (VILELLA e MATTOS, 1975). 
As vazões mínimas podem ser entendidas como os menores valores de vazão das séries analisadas e são muito utilizadas para o planejamento de recursos hídricos, na elaboração de planos de abastecimento de água, aproveitamento hídrico para a geração de energia, outorgas de concessão, irrigação, entre outros (GRANEMANN, 2016). As vazões máximas podem ser entendidas como os maiores valores de vazão verificados em uma série, são utilizadas para a previsão de enchentes, para a construção de obras hidráulicas, como condutos, bueiros, reservatórios, etc (TUCCI, 2013). Já as vazões médias, segundo Tucci (2013) são os valores médios de vazão de um rio ou de uma seção deste, sendo que, a vazão média anual de um rio é a média de todos os valores diários e, "a vazão média de um longo períodoQ1p é a média das vazões médias anuais ou a média das médias" (p. 579).

O cálculo e interpretação da vazão de um rio, ou da área de captação referente a seção de um rio, contribuem para o planejamento - a curto, médio e longo prazo - e na tomada de decisão sobre a sua utilização."De um modo geral, os estudos hidrológicos baseiam-se na quase repetição dos regimes de precipitação e de escoamento dos rios, ao longo do tempo" (PINTO, 1976, p. 05). Entretanto, para isso, são necessários uma distribuição de postos de monitoramento em uma dada bacia, bem como da qualidade e da consistência dos dados registrados nestes postos.Com relação a densidade de postos de monitoramento, no Brasil, a média de postos de medição de vazões, para o ano de 1976 era de um posto para cada $4.000 \mathrm{~km}^{2}$ (PINTO, 1976). Esta distribuição está muito abaixo do ideal, é necessário que, cada vez mais seja ampliada a rede de estações de coleta de dados, além da manutenção dos postos já instalados pois, segundo Naghettini e Pinto (2007), a manutenção e a densidade dos postos de coleta é que darão qualidade aos estudos hidrológicos.

A partir da aquisição dos dados brutos de vazão, é possível aplicar técnicas de estatísticas para o tratamento dessas medidas afim de refinar o tratamento e análise da série dos dados e, trazer mais informações sobre a variável, mais do que a própria tabela original de dados brutos (MORETTIN \& BUSSAB, 2004). As técnicas estatísticas realizadas nesse trabalho foram a de Assimetria e Curtose.

A assimetria é um valor adimensional que "[...] reflete e acentua a contribuição acumulada dos desvios positivos e negativos, em relação à média amostral" (NAGHETTINI e PINTO, 2007, p. 36). Pode ser entendida como o grau de desvio ou afastamento da simetria de uma distribuição em função da média. $\mathrm{O}$ grau de assimetria de uma amostra se dá pela diferença nos valores entre a média, a moda e a mediana, por meio do cálculo do coeficiente de assimetria.

Conhecer o grau e a intensidade da assimetria revela informações importantes que apenas o conjunto de dados brutos não seria capaz. A distribuição pode ser simétrica ou assimétrica e, dentro da classificação assimétrica, pode ser positiva ou negativa. Uma distribuição é simétrica quando seus valores de média, 
moda e mediana são coincidentes ou são muito próximas de 0 . Uma distribuição é assimétrica quando os valores de média, moda e mediana não são equivalentes, entretanto, quando o valor da moda é maior que os valores de mediana emédia, diz-se que a distribuição apresenta assimetria à esquerda (ou positiva). Uma distribuição assimétrica à direita (ou negativa), o valor da média é maior que o da mediana, que por sua vez, é maior que o da moda.

Quando uma distribuição possui assimetria à esquerda, verifica-se que há mais ocorrências de valores abaixo da média, entretanto, os valores que são acima da média, e de pouca ocorrência, influenciam no valor da média da distribuição, ou seja, um evento extremo que esteja muito acima da média tem influência direta no comportamento da média, por isso deve ser dado atenção a esses valores. Da mesma forma em distribuição assimétrica à direita, há maiores ocorrências de valores acima da média, entretanto, os valores abaixo da média merecem atenção pois influenciam diretamente no comportamento da média da distribuição.

A curtose é uma medida adimensional que verifica o grau de achatamento de uma distribuição em relação a uma distribuição padrão (curva normal). O valor obtido "[...] indica quão aglomerados estão os pontos amostrais em torno da média, tem-se também a noção da distribuição dos valores muito distantes daquele valor central e, por conseguinte, das frequências que se concentram nas caudas inferior e superior" (NAGHETTINI e PINTO, 2007, p. 37).

Em uma distribuição normal, a curva de dados tem valor de 0,263 , sendo denominada de mesocúrtica, de modo que, os elementos estão distribuídos relativamente ao longo da amostra, tendo uma média concentração na parte central e uma concentração menor nas caudas. Se o valor de curtose de uma curva for menor que 0,263, diz-se que os elementos estão fortemente concentrados na parte central da distribuição, a curva tem uma aparência pontiaguda e é denominada de leptocúrtica. Já numa distribuição platicúrtica, o coeficiente de curtose é maior que 0,263 e, os elementos estão bem distribuídos ao longo da amostra, sendo que, a curva é mais achatada, tendo uma curva menos acentuada.

Diante do exposto, neste trabalho serão calculados os coeficientes de assimetria e de curtose dos valores de vazões, considerando-se as vazões médias mensais da bacia do Rio Preto-BA, no intervalo de 19702015.

\section{Localização da Área de estudo}

A Bacia do Rio Preto localiza-se no noroeste do estado da Bahia, fazendo fronteira com o Tocantins ao oeste e, com o Piauí ao norte. É um dos afluentes do Rio Grande (BA), que faz parte da Bacia 


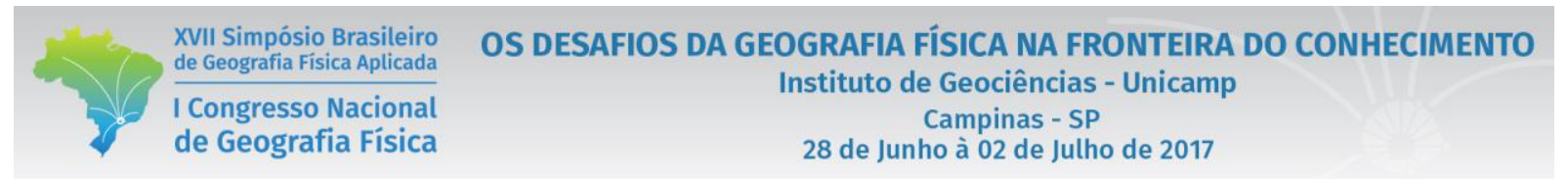

Hidrográfica do Rio São Francisco. O curso d'água do Rio Preto passa por três municípios, Formosa do Rio Preto,Santa Rita de Cássia e Mansidão. Esses municípios juntos somam 68.504 habitantes, segundo população estimada de 2016, pelo IBGE (Instituto Brasileiro de Geografia e Estatística).

Mapa 01 - Localização da Bacia Hidrográfica do Rio Preto - BA

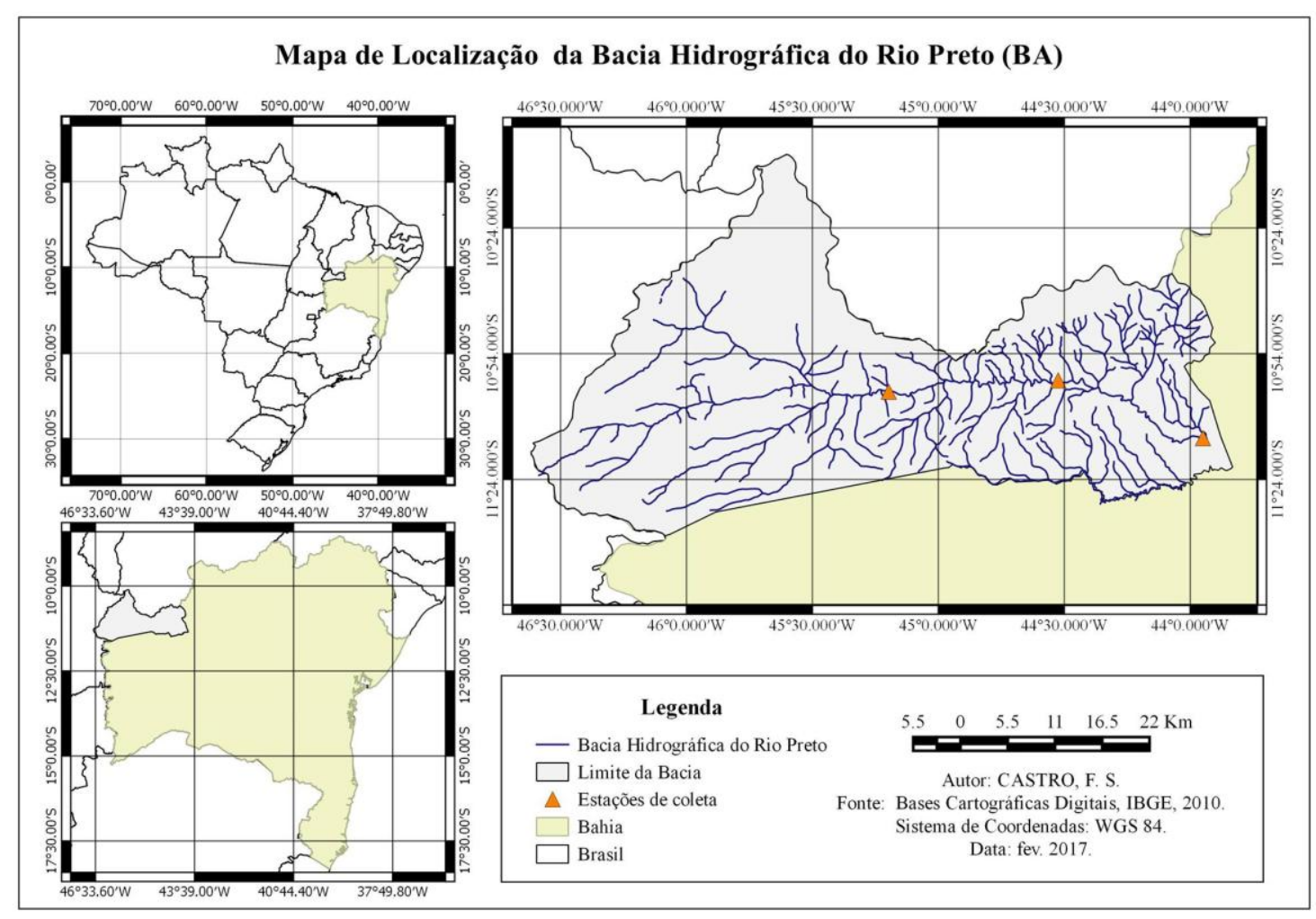

Fonte: IBGE (2010); Org. CASTRO (2017)

\section{Metodologia de trabalho}

Primeiramente, foi realizado o referencial teórico acerca da temática abordada.

Os dados analisados foram obtidos da ANA (Agência Nacional das Águas) no sítio hidroweb- Sistemas de Informações Hidrológicas. Ao longo do curso do Rio Preto, foram localizados 12 postos de medição, mas apenas três deles estão com dados consistentes. Apenas os postos fluviométricos sob responsabilidade da ANA e da CPRM (Companhia de Pesquisa de Recursos Minerais - Serviço Geológico do Brasil) apresentam dados consistentes, os demais postos, sob responsabilidade de outros órgãos, os dados coletados não são consistentes. 
Quadro I - Relação dos postos fluviométricos do Rio Preto-BA

\begin{tabular}{|c|c|c|c|c|c|}
\hline Código & $\begin{array}{c}\text { Nome do } \\
\text { posto }\end{array}$ & Município & Latitude & Longitude & $\begin{array}{c}\text { Série de } \\
\text { dados }\end{array}$ \\
\hline 46790000 & $\begin{array}{c}\text { Formosa do } \\
\text { Rio Preto }\end{array}$ & $\begin{array}{c}\text { Formosa do } \\
\text { Rio Preto }\end{array}$ & $11^{\circ} 03^{\prime} 05^{\prime}{ }^{\prime} \mathrm{S}$ & $45^{\circ} 11^{\prime} 497^{\prime}, \mathrm{W}$ & $\begin{array}{c}1977-2002 \\
2004-2015\end{array}$ \\
\hline 46830000 & Ibipetuba & $\begin{array}{c}\text { Santa Rita de } \\
\text { Cássia }\end{array}$ & $11^{\circ} 0^{\prime} 21^{\prime}$ ' S & $44^{\circ} 31^{\prime} 27^{\prime}$ ' W & $1970-2015$ \\
\hline 46870000 & $\begin{array}{c}\text { Fazenda } \\
\text { Porto Limpo }\end{array}$ & Mansidão & $11^{\circ} 14^{\prime} 08^{\prime}$ ' S & $43^{\circ} 56^{\prime} 58^{\prime}$ ' W & $\begin{array}{c}1977-1989 \\
1993-2015\end{array}$ \\
\hline
\end{tabular}

Fonte: ANA-Hidroweb; Org. Petrucci (2017)

Após a obtenção dos dados, eles foram processados no software SisCAH1.0 - Sistema Computacional para Análise Hidrológica, em que foram determinadas as médias mensais dos postos.

Os cálculos referentes aos coeficientes de assimetria foram elaborados em planilha eletrônica do Microsoft Excel. Há diversas fórmulas para o cálculo do coeficiente de assimetria, entretanto, será utilizado o Coeficiente de Pearson, em que: $A S=$ coeficiente de variação, $\bar{x}=$ é a média da distribuição; $\mathrm{x}_{\mathrm{mo}}=$ é a moda da distribuição; $\mathrm{S}$ = é o desvio padrão.

$$
\mathrm{AS}=\frac{\overline{\mathrm{X}}-\mathrm{X}_{\mathrm{mo}}}{\mathrm{S}}
$$

Quando o coeficiente de variação é igual a 0 , diz-se que a distribuição é simétrica, sendo que, os valores de média, mediana e moda da distribuição coincidem. A distribuição pode ser assimétrica positiva, tendo o valor da média, maior que os valores de mediana e moda. A distribuição pode ser assimétrica negativa, o valor da moda é maior que o valor da mediana, que por sua vez é maior que a média. Se a distribuição for assimétrica, ela pode ser classificada em Assimetria Fraca quando: $0<|\mathrm{AS}|<0,15$; Assimetria Moderada: $0,15<|\mathrm{AS}|<1$; e Assimetria Forte se: $|\mathrm{AS}|>1$.

Para o cálculo da assimetria, por meio do Coeficiente de Pearson, foram necessários realizar o cálculo da média aritmética, a moda, a mediana e o desvio padrão. Após realizados os cálculos, substitui-seos valores correspondentes na fórmula do coeficiente de Pearson.

O coeficiente de curtose pode ser calculado, por meio da fórmula:

$$
C=\frac{Q_{3}-Q_{1}}{2\left(P_{90}-P_{10}\right)}
$$

Em que: $\mathrm{C}=$ coeficiente de curtose; $\mathrm{Q}_{1}=$ primeiro quartil; $\mathrm{Q}_{3}=$ terceiro quartil; $\mathrm{P}_{10}=$ décimo percentil; $\mathrm{P}_{90}$ $=$ nonagésimo percentil. 
$\mathrm{O}$ valor do coeficiente de curtose de uma distribuição normal é de $\mathrm{C}=0,263$, que corresponde a uma curva mesocúrtica. Se o valor for menor que 0,263 significa que a curva é leptocúrtica. Se o coeficiente for maior que 0,263 quer dizer que a curva é platicúrtica.

Para ser calculado o coeficiente de curtose, é necessário conhecer os valores do primeiro e terceiro quartil, e os valores do décimo e nonagésimo percentil.

$$
\begin{array}{ccc} 
& 1^{\circ} \text { Quartil }\left(Q_{1}\right): & \bullet 10^{\circ} \operatorname{percentil}\left(P_{10}\right): \\
Q_{1}=l_{*}+\frac{\left[\frac{\sum f i}{4}-F \text { ant. }\right] * h}{f i} & P_{10}=l_{*}+\frac{\left[10 * \frac{\sum f i}{100}-F \text { ant. }\right] * h}{f i} \\
& -\quad 3^{\circ} \text { Quartil }\left(Q_{3}\right): & \bullet \quad 90^{\circ} \operatorname{percentil~}\left(P_{90}\right): \\
Q_{3}= & l_{*}+\frac{\left[3 * \frac{\sum f i}{4}-F \text { ant. }\right] * h}{f i} & P_{90}=l_{*}+\frac{\left[90 * \frac{\sum f i}{100}-F \text { ant. }\right] * h}{f i}
\end{array}
$$

Sendo que 1*: Limite inferior da classe; fi: frequência absoluta; F ant.: Frequência acumulada anterior; h: amplitude da classe;fi: Frequência da Classe (classe determinada pela soma da Frequência Absoluta/divisor).

\section{Resultados e Discussões}

Para o período de janeiro de 1977 a dezembro de 2015, a vazão média calculada para o posto Formosa do Rio Preto foi de 96,93 m³/s. O maior valor de vazão máxima média ocorreu no mês de fevereiro de 1980, com um total de $221,52 \mathrm{~m}^{3} / \mathrm{s}$ e, de outro modo, a menor vazão mínima média de $62,70 \mathrm{~m}^{3} / \mathrm{s}$ ocorreu em setembro de 2015. Verifica-se uma amplitude significativa, de 158,82 $\mathrm{m}^{3} / \mathrm{s}$, entre as vazões máxima média e mínima média.

Os postosIbipetuba e Fazenda Porto Limpo possuem um comportamento do regime de vazões semelhante, quanto ao período de maiores e menoresvazões mensais. O posto Ibipetuba, localizado no município de Santa Rita de Cássia tem vazão média, do período de 1970 a 2015, de 96,26 m³/s. A vazão máxima mensal foi verificado no mês de fevereiro de 1980, com um volume total de 311,28 m³/s e vazão mínima mensal média foi de $61,49 \mathrm{~m}^{3} / \mathrm{s}$ verificada em outubro de 2008. A amplitude total entre o mês de maior vazão e o mês de menor vazão foi de $249,79 \mathrm{~m}^{3} / \mathrm{s}$.

O posto Fazenda Porto Limpo é o que teve a maior média mensal entre os referidos postos, chegando a $370,7 \mathrm{~m} 3 / \mathrm{s}$ no mês de fevereiro de 2008 e menor média mensal em outubro de 2008 , com $66,71 \mathrm{~m}^{3} / \mathrm{s}$. A 
amplitude entre o mês de maior vazão com o mês de menor vazão foi de $304,05 \mathrm{~m} 3 / \mathrm{s}$. A média geral do posto é de $106,09 \mathrm{~m}^{3} / \mathrm{s}$.

Tabela 1 - Médias mensais dos postos de medição do Rio Preto/BA

\begin{tabular}{c|c|c|c|c|c|c|c|c|c|c|c|c}
\hline \multirow{2}{*}{ Postos de Medição } & \multicolumn{10}{c}{ Médias Mensais 1970-2015 } \\
\cline { 2 - 12 } & Out & Nov & Dez & Jan & Fev & Mar & Abr & Mai & Jun & Jul & Ago & Set \\
\hline Formosa do Rio Preto & 82,49 & 97,82 & 113,58 & 118,73 & 121,02 & 116,78 & 106,75 & 91,08 & 83,09 & 79,66 & 76,91 & 75,72 \\
Ibipetuba & 79,57 & 94,04 & 108,55 & 115,62 & 122,41 & 117,31 & 109,35 & 93,78 & 84,60 & 80,04 & 76,20 & 73,92 \\
Faz. Porto limpo & 83,26 & 101,55 & 124,45 & 133,84 & 142,14 & 135,79 & 124,17 & 100,84 & 89,15 & 83,51 & 79,25 & 76,57 \\
\hline
\end{tabular}

Fonte: ANA; Org. Petrucci E. (2017)

A tabela 1 apresenta os valores médios mensais dos três postos analisados, de 1970 a 2015, portanto as médias das médias, para se ter um parâmetro sobre as médias gerais. Os dados brutos que foram analisados, serviram de base para a construção dessa tabela. A partir disso, é possível verificar o posto Fazenda Porto Limpo é o que possui as maiores médias mensais dos três postos, com pico de vazão no mês de fevereiro, com 142,14 m³/s e, o posto Ibipetuba registou a menor vazão média, com 73,92 m³/s no mês de setembro. O gráfico 1, evidencia a diferença entre os postos fluviométricos do Rio Preto-BA.

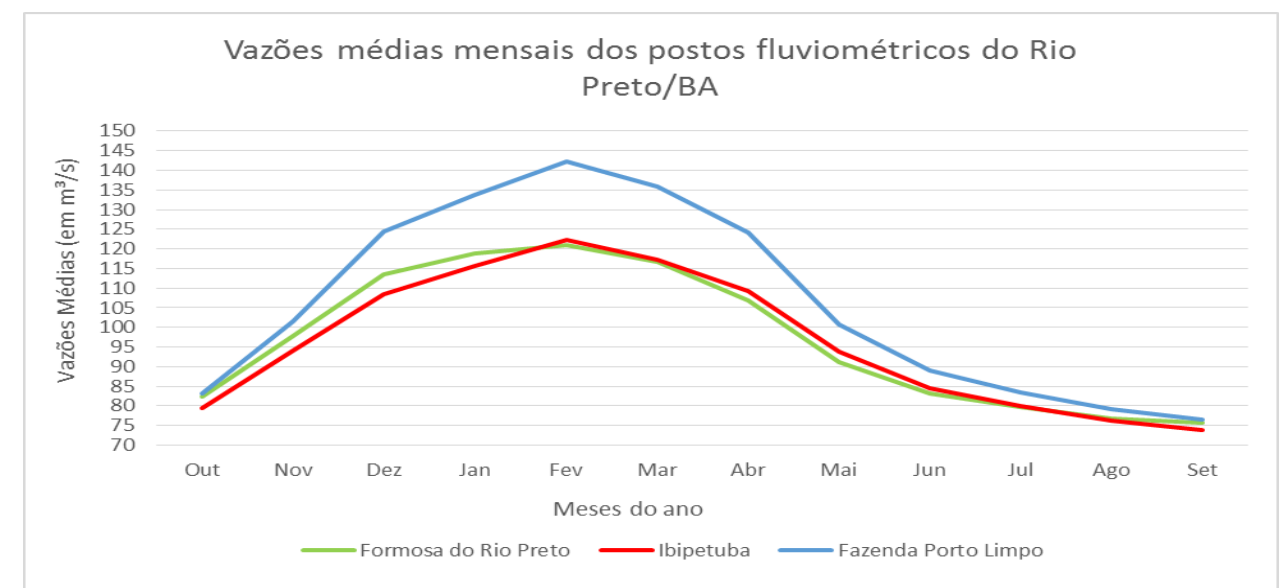

Gráfico 1 - Comparação entre as médias mensais dos postos fluviométricos do Rio Preto-BA 


\section{OS DESAFIOS DA GEOGRAFIA FÍSICA NA FRONTEIRA DO CONHECIMENTO \\ Instituto de Geociências - Unicamp \\ Campinas - SP \\ 28 de Junho à 02 de Julho de 2017}

Fonte: ANA; Org. Petrucci (2017)

Analisando o comportamento das vazões no gráfico, é possível observar que o mês de outubro marca o início do período de aumento dos valores de vazões culminando com o valor máximo (pico) no mês de fevereiro $\left(142,14 \mathrm{~m}^{3} / \mathrm{s}\right)$. De modo contrário, o período crítico, de menores vazões, se entendeu de junho a outubro sendo o mês de setembro o de menor valor médio $\left(75,07 \mathrm{~m}^{3} / \mathrm{s}\right)$.

A tabulação e os cálculos para as determinações dos coeficientes de Assimetria e Curtose, incluindo as suas variáveis, foram realizados no software Microsoft Office Excel 2013.

\section{- $\quad$ Formosa do Rio Preto:}

Para o cálculo da assimetria, primeiramente foi necessário encontrar os valores de média aritmética, moda e desvio padrão da série de dados. Com isso, foram encontrados os seguintes valores: Média: 96,93; Moda: 139,53; e Desvio Padrão: 23,44. A seguir, esses valores foram substituídos na fórmula do coeficiente de assimetria de Pearson:

$$
\mathrm{AS}=\frac{\overline{\mathrm{X}}-\mathrm{X}_{\mathrm{mo}}}{\mathrm{S}}=\frac{96,93-139,53}{23,44}=-1,817
$$

Com o valor encontrado de $-1,817$, é verificado que a distribuição não é simétrica, apresentando forte assimetria positiva (ou à esquerda). Há concentração de ocorrência de valores de vazões abaixo da média $(96,93)$. Apesar de haver mais ocorrência de valores abaixo da média, há uma baixa ocorrência de valores muito acima da média, na cauda à direita, e tem correlação direta com a determinação dos valores de medida de posição.

Afim de melhor visualização dos dados, foi criado um histograma para a distribuição. Para a criação do histograma foi necessário realizar a divisão da amostra em classes e a frequência absoluta desses valores nas respectivas classes.

Gráfico 2: Histograma Formosa do Rio Preto-BA 


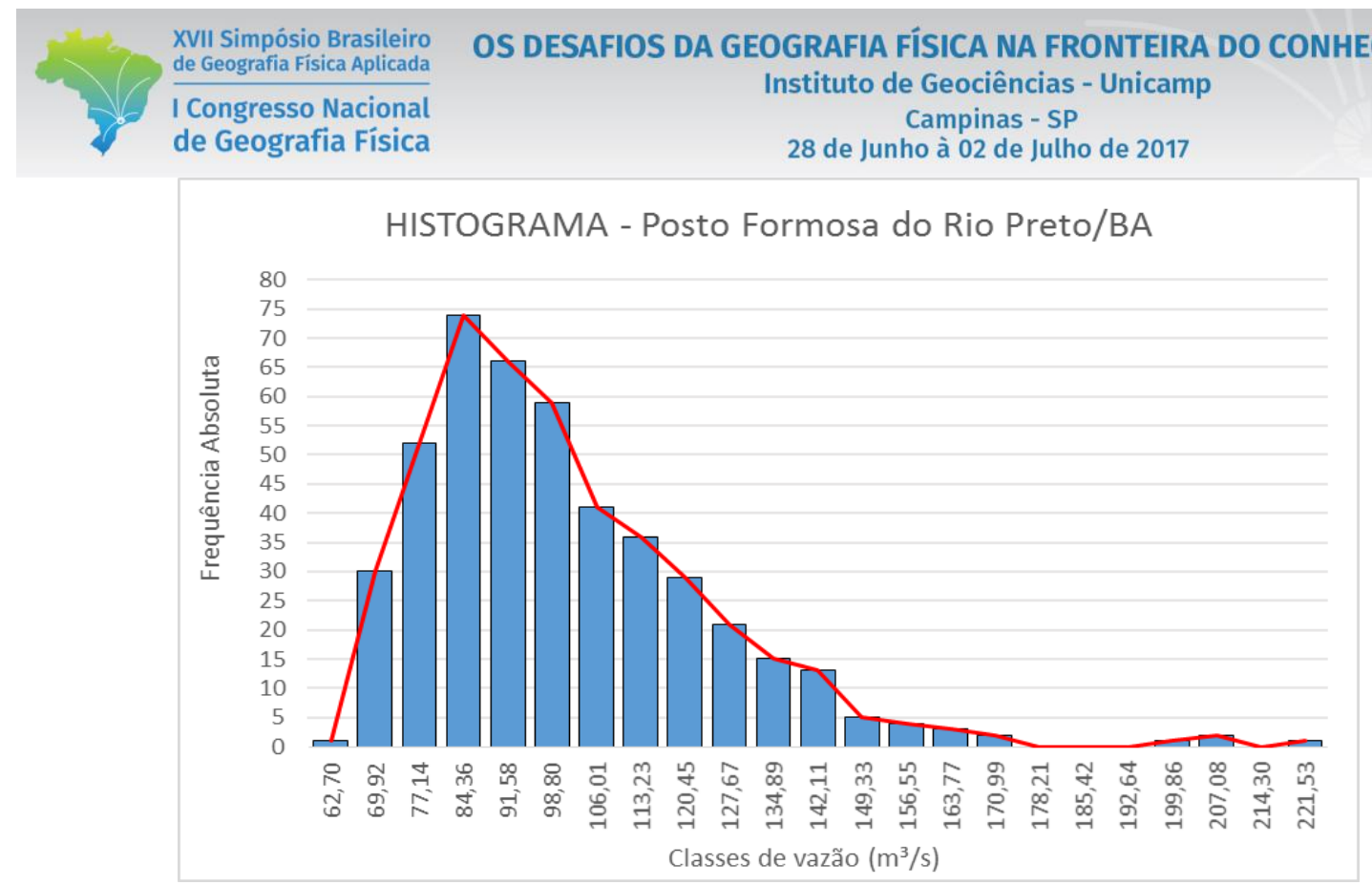

Fonte: ANA; org. Petrucci (2017)

Para o cálculo do coeficiente de curtose, é necessário, inicialmente, organizar a amostra, de modo que sejam determinadas as classes e as frequências absoluta $\left(F_{i}\right)$ e acumulada $(F)$ de cada classe. Para organizar a amostra em classes, é preciso ter o número total de elementos $(\mathrm{N})$, o valor máximo (MÁX) e valor mínimo (MÍN) de ocorrência, e a amplitude (h), que é a diferença entre o maior e o menor valor encontrado. A partir disso, calcula-se a quantidade de classes $(\sqrt{N})$, e o intervalo de cada classe $(h / \sqrt{N})$. Após a organização dos dados, a próxima etapa é descobrir os valores do $1^{\circ}$ quartil $\left(\mathrm{Q}_{1}\right), 3^{\circ}$ quartil $\left(\mathrm{Q}_{3}\right)$, $10^{\circ}$ percentil $\left(\mathrm{P}_{10}\right)$ e $90^{\circ}$ percentil $\left(\mathrm{P}_{90}\right)$.

$$
C=\frac{Q_{3}-Q_{1}}{2\left(P_{90}-P_{10}\right)}=\frac{109,67-80,14}{2(127,93-71,93)}=0,263
$$

Após calcular as variáveis, foram encontrados os seguintes valores: $\mathrm{Q}_{1}=80,14$ / $\mathrm{Q}_{3}=109,67$ / $\mathrm{P}_{10}=71,93$ / $\mathrm{P}_{90}=127,93$. Com isso, foi encontrado o seguinte coeficiente de curtose:

O valor do coeficiente de curtose foi 0,263 o que significa que a distribuição é uma curva mesocúrtica.

\section{- Ibipetuba}

A partir da série de dados, foi encontrado os seguintes valores: Média: 96,26, Moda: 69,53 e Desvio Padrão: 24,78. Essas medidas de posição em dados amostrais são a base para o cálculo do coeficiente de assimetria.

$$
\mathrm{AS}=\frac{\overline{\mathrm{X}}-\mathrm{X}_{\mathrm{mo}}}{\mathrm{S}}=\frac{96,26-69,53}{24,78}=1,078
$$




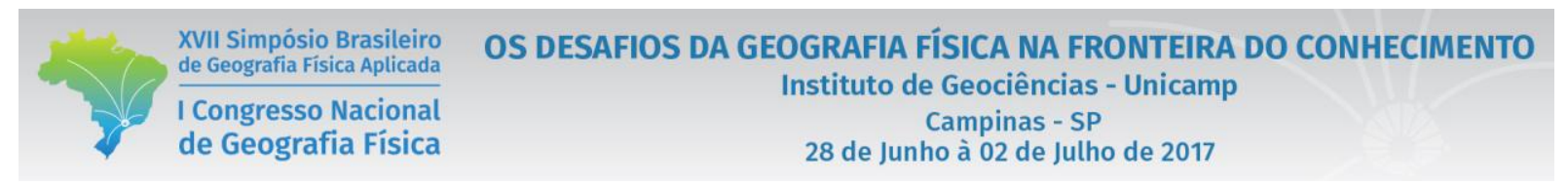

O valor encontrado de 1,078 configura a distribuição como assimétrica negativa, ou à direita. Possui uma forte assimetria. Nesse posto, o valor da média é maior que os valores da moda e da mediana. Para uma melhor visualização dos dados, segue abaixo o histograma da série (Gráfico 03):

A partir do gráfico 3, é possível verificar que há maior concentração dos valores de vazão menores do que a média $(96,26)$, entretanto, os valores maiores que a média, e de baixa ocorrência são fundamentais para a configuração do histograma, bem como tem influência direta na sua determinação.

Gráfico 3: Histograma Ibipetuba-BA

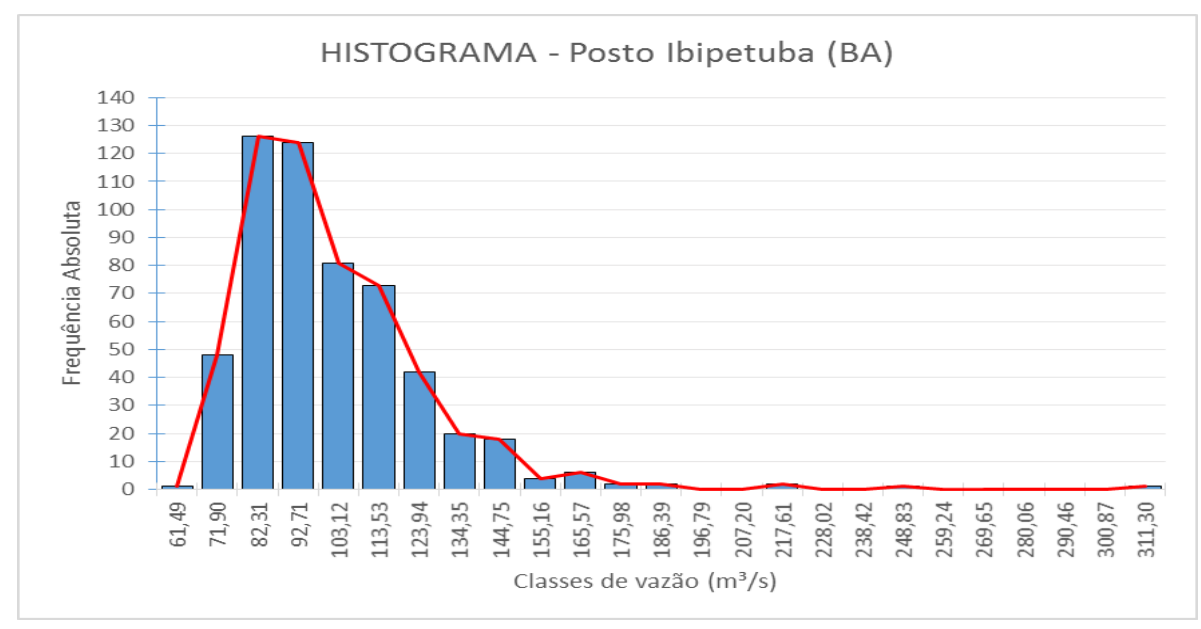

Fonte: ANA; org. Petrucci (2017)

Para o cálculo do coeficiente de curtose, foram encontrados os seguintes valores das variáveis: $\mathrm{Q}_{1}=73,23$ / $\mathrm{Q}_{3}=107,86 / \mathrm{P}_{10}=72,40 / \mathrm{P}_{90}=124,36$. Com eles, pode-se calcular a curtose da distribuição:

$$
C=\frac{Q_{3}-Q_{1}}{2\left(P_{90}-P_{10}\right)}=\frac{107,86-79,23}{2(124,36-72,40)}=0,275
$$

Com isso, é possível verificar que a distribuição apresenta uma Curva Platicúrtica, ou seja, os valores, fazendo com que ela seja mais aberta, ou mais achatada. No histograma do posto (gráfico 3) é possível visualizar a concentração dos dados nas $3^{\circ}$ e $4^{\circ}$ classes da amostra.

\section{- $\quad$ Fazenda Porto Limpo}

No $3^{\circ}$ posto fluviométrico, a partir da série de dados, foram encontrados os seguintes valores das medidas de posição: Média: 106,09; Moda: 98,20 e Desvio Padrão: 34,54. A partir deles, é possível calcular o coeficiente de assimetria:

$$
\mathrm{AS}=\frac{\overline{\mathrm{X}}-\mathrm{X}_{\mathrm{mo}}}{\mathrm{S}}=\frac{106,09-98,20}{34,54}=0,228
$$


O valor encontrado no coeficiente de assimetria revelou que a distribuição possui moderada assimetria negativa, ou à direita, sendo que, os valores acima da média são de pouca ocorrência e estão concentrados na cauda à direita, podendo ser verificado pelo gráfico 4.

Gráfico 4: Histograma Fazenda Porto Limpo-BA

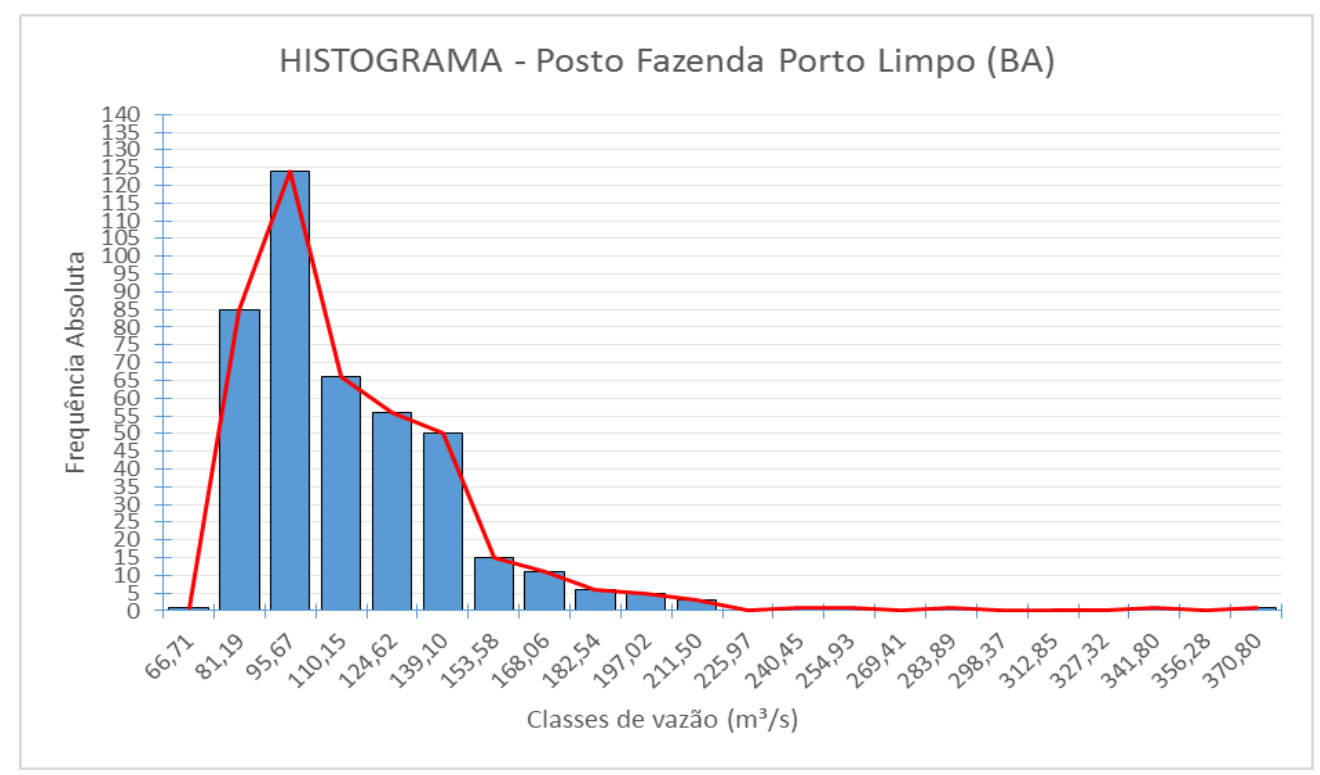

Fonte: ANA; org. Petrucci (2017)

Para o cálculo do coeficiente de curtose, foram encontrados os seguintes valores das variáveis: $\mathrm{Q}_{1}=83,61$ $/ \mathrm{Q}_{3}=121,59 / \mathrm{P}_{10}=73,81 / \mathrm{P}_{90}=141,32$.

$$
C=\frac{Q_{3}-Q_{1}}{2\left(P_{90}-P_{10}\right)}=\frac{121,59-83,61}{2(141,32-73,81)}=0,281
$$

O valor encontrado de coeficiente de curtose evidencia que a distribuição apresenta uma curva Platicúrtica, em que, a curva não apresenta forte concentração em determinada classe e os dados são mais espaçados ao longo da distribuição.

\section{Conclusão e Considerações Finais}

A estatística básica auxilia na análise de variáveis e dados ambientais e proporciona uma visualização sobre o comportamento hidrológico de uma bacia hidrográfica. A análise estatística sobre as variáveis 
contínuas de vazões médias mensais explora campos e possibilita uma proximidade entre os dados e as variações sobre eventos hidrológicos, verificados no plano do real.

O posto Fazenda Porto Limpo é o que apresentou a maior amplitude entre a máxima média e a mínima média mensal. A amplitude foi de 304,05 m³/s., sendo este um indicativo de problema quanto se refere a regulação hídrica, ou seja, não há uma eficiência do sistema hidrológico-hidrogeológico, principalmente na função de reservatório. Esta característica condiciona eficiência do escoamento superficial (cheias) em contrapartida a redução dos coeficientes de infiltração (fluxo de base reduzido).

A partir do cálculo do Coeficiente de Assimetria, foi verificado que os postos Ibipetuba e Fazenda Porto Limpo apresentaram assimetria negativa ou à direita, com intensidade forte e moderada, respectivamente. O posto Formosa do Rio Preto apresentou forte assimetria positiva, ou à esquerda.

O Coeficiente de Curtose revelou que a curva de distribuição dos dados do posto Formosa do Rio Preto é mesocúrtica, ou seja, os dados estão bem distribuídos ao longo da curva, apresentando valores normais de distribuição. Os postos Ibipetuba e Fazenda Porto Limpo apresentaram uma curva de distribuição Platicúrtica. Com isso, verifica-se que a curva de distribuição do posto Fazenda Porto Limpo é menos acentuada do que o dos postos Ibipetuba e Formosa do Rio Preto.

Ao longo do desenvolvimento do trabalho, foi possível verificar que os materiais e métodos foram satisfatórios para o tratamento estatístico dos dados e para os cálculos dos coeficientes de Assimetria e Curtose.

\section{Agradecimento}

Agradecimento à FAPEMIG (Fundação de Amparo à Pesquisa do Estado de Minas Gerais) pelo apoio à realização da pesquisa e apresentação dos resultados no XVII Simpósio Brasileiro de Geografia Física Aplicada e I Congresso Nacional de Geografia Física.

\section{Bibliografia}

ANA. Agência Nacional das Águas. Disponível em: 〈http://hidroweb.ana.gov.br/>. Acesso em: 18 jan. 2017.

GRANEMANN, A. R. B. Análise de frequência de vazões mínimas. 2016. 61 f. Dissertação (Mestrado em Engenharia de Recursos Hídricos e Ambiental). Departamento de Hidráulica e Saneamento - Setor de Tecnologia, Universidade Federal do Paraná, Curitiba, 2016.

MORETTIN, P. A.; BUSSAB, W. O. Estatística Básica.5 ed. São Paulo: Saraiva, 2004.

NAGHETTINI, M.; PINTO, E. J. A. Hidrologia Estatística. Belo Horizonte: CPRM, 2007. 552 p. 


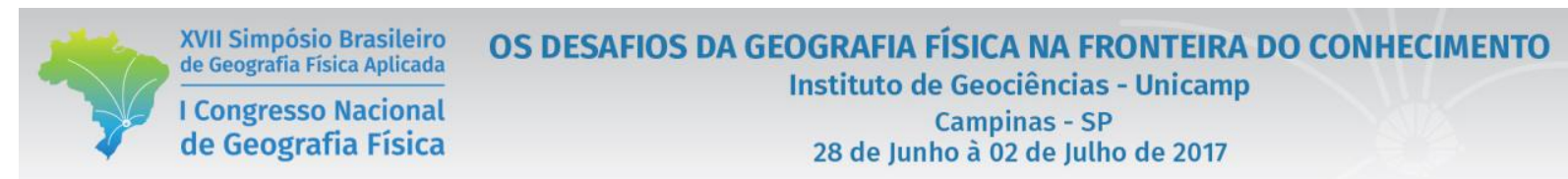

PINTO, N. L. S.; HOLTZ, A. C. T.; MARTINS, J. A.; GOMIDE, F. L. S. Hidrologia Básica. São Paulo: Editora Edgard Blücher, 1976.

TUCCI, C. E. M. (org). Hidrologia: ciência e aplicação. 4 ed. 5 reimp. Porto Alegre: Editora da UFRGS/ABRH, 2013.

VILELLA, S. M.; MATTOS, A. Hidrologia aplicada. São Paulo: McGraw-Hill do Brasil, 1975.

- IBGE. Instituto Brasileiro de Geografia e Estatística. Diretoria de Pesquisas - DPE - Coordenação de População

e Indicadores $\quad$ Sociais $\quad-\quad$ COPIS. Disponível em:

<http://www.ibge.gov.br/home/estatistica/populacao/estimativa2016/estimativa_tcu.shtm〉. Acesso em 14 de fevereiro de 2017. 